\title{
Exposure as Collected Pre-specified
}

National Cancer Institute

\section{Source}

National Cancer Institute. Exposure as Collected Pre-specified. NCI Thesaurus. Code C117477.

An indication or description that the collected exposure was previously determined, characterized, or detailed. 